\title{
Perda dos cotilédones em diferentes épocas no crescimento inicial do feijoeiro
}

\author{
Allan de Marcos Lapaz', Luiz Felipe de Melo Santos², Camila Hatsu Pereira Yoshida ${ }^{3}$, Paulo \\ Alexandre Monteiro de Figueiredo ${ }^{2}$, Ronaldo da Silva Viana ${ }^{2}$ \& Lucas Aparecido Manzani Lisboa ${ }^{2}$
}

\author{
1 Universidade Federal de Dracena, Faculdades de Dracena, Rua Bahia, 332, Bairro Metrópole, CEP 17900-000 - Dracena, São Paulo, \\ Brasil.allanlapaz60@gmail.com.br \\ 2 Universidade Estadual Paulista, Faculdade de Ciências Agrárias e Tecnológicas, Rod. Comandante João Ribeiro de Barros, km 651 , \\ Bairro das Antas, CEP 17900-000 - Dracena, São Paulo, Brasil. felipemelo.biologia@gmail.com; paulofigueiredo@dracena.unesp.br; \\ ronaldo@dracena.unesp.br; lisboa@dracena.unesp.br \\ ${ }^{3}$ Universidade do Oeste Paulista, Rodovia Raposo Tavares, km 572, Bairro Limoeiro, CEP 19067-175 \\ Presidente Prudente, São Paulo, Brasil. camila.anjel@gmail.com
}

Recebido em 21.IX.2016

Aceito em 08.VIII.2017

DOI $10.21826 / 2446-8231201772216$

RESUMO - Este trabalho teve por objetivo analisar o efeito da perda dos cotilédones em diferentes épocas do crescimento inicial do feijoeiro. O delineamento experimental foi inteiramente casualizado em esquema fatorial de $2 \times 5$, plântulas com zero e um cotilédone, interagindo com cinco épocas de extrações: zero, um, dois, quatro e seis dias após a germinação, com cinco repetições compostas por três plântulas. Após os 15 dias foram avaliados os seguintes parâmetros: comprimento médio de raiz e parte aérea; diâmetro médio do caule; área foliar; massa seca total da parte aérea e raiz; diâmetro do floema e xilema; espessura da epiderme abaxial e adaxial. A remoção dos cotilédones no desenvolvimento inicial do feijoeiro influência todos os parâmetros avaliados neste trabalho, exceto o diâmetro médio do caule com um cotilédone. A remoção dos cotilédones nos primeiros dias de extrações dificulta o desenvolvimento inicial do feijoeiro, assim como o torna mais suscetível ao meio.

Palavras-chave: estresse, morfologia vegetal, nutrientes, Phaseolus vulgaris L.

\begin{abstract}
Loss of cotyledons in different stages in initial bean growth. The objective of this work was to analyze the effect of cotyledon loss at different times of initial bean growth. The experimental design was completely randomized in a factorial scheme of $2 \times 5$, seedlings with zero and one cotyledon, interacting with five extraction stages: zero, one, two, four, and six days after germination, with five replicates composed of three seedlings. After 15 days, the following parameters were evaluated: mean root and shoot length; mean stem diameter; leaf area; total shoot and root dry mass; phloem and xylem diameter; and thickness of abaxial and adaxial epidermis. Removing cotyledons during the initial development of the bean plant influenced all the parameters evaluated in this work, except the mean diameter of the stem with one cotyledon. The removal of cotyledons in the first days of extractions hinders the initial development of the plant, as well as making it more susceptible to the environment.
\end{abstract}

Keywords: stress, nutrients, plant morphology, Phaseolus vulgaris L.

\section{INTRODUÇÃO}

Dentre as leguminosas, o feijão comum (Phaseolus vulgaris L.) destaca-se no cardápio da alimentação humana, abarcando $50 \%$ das leguminosas consumidas no mundo. $\mathrm{O}$ fato deste produto possuir custo baixo, torna-se uma alternativa no consumo de proteína para as populações de baixa renda na América Latina e na África (Alwathnani et al. 2012). No Brasil, esta cultura é um dos alimentos mais tradicionais, motivo pelo qual o plantio se estende por todo seu território, tornando-se o maior produtor e consumidor mundial dessa leguminosa alimentar (Barbosa \& Gonzaga 2012).

O feijoeiro é uma planta que possui dois cotilédones em suas sementes. Os cotilédones participam do processo fotossintético e exercem uma grande influência no desenvolvimento inicial e crescimento da plântula ao definir uma estratégia sincronizada na degradação de suas reservas, atuando no suprimento da demanda de energia e de nutrientes proveniente da plântula até as suas folhas estabelecerem os processos fotossintéticos (Sakpere et al. 2015).

Os cotilédones podem sofrer danos ainda nas sementes, antes mesmo de ocorrer a germinação, o que pode causar uma redução na germinação e no desenvolvimento inicial da plântula, ainda, dependendo da severidade dos danos, até mesmo levá-la a morte em suas fases inicias de estabelecimento (Yi et al. 2015).

Após a germinação, os cotilédones podem ter sua massa danificada pela herbivoria, resultando no comprometimento do desenvolvimento inicial devido à redução da quantidade de tecido fotossintetizante e de reserva (Hayashi et al. 2012). Por outro lado, quando a planta apresenta capacidade de sobreviver diante desses danos, mesmo havendo 
a perda completa de seus cotilédones, é um indicativo da adaptabilidade da espécie em se recuperar dos danos sofridos na fase inicial de seu desenvolvimento (Iortsuun et al. 2008).

Diante do exposto, esse trabalho teve por objetivo analisar o efeito da perda dos cotilédones em diferentes épocas do crescimento inicial do feijoeiro.

\section{MATERIAL E MÉTODOS}

No mês de junho de 2016 foi realizado o presente experimento na Faculdade de Ciências Agrárias e Tecnológicas da Universidade Estadual Paulista "Júlio de Mesquita Filho", localizada no município de Dracena, Estado de São Paulo, com coordenadas geográficas $21^{\circ} 27^{\prime} 34,474^{\prime}$ S e $51^{\circ} 33^{\prime} 19,167^{\prime}$ 'W, com altitude média de $400 \mathrm{~m}$ acima do nível do mar.

O experimento foi instalado em casa de vegetação tipo arco, com pé direito de seis metros, coberta com plástico filme transparente difusor de luz, com espessura de 1000 micra e as suas laterais eram revestidas por uma tela tipo sombrite com $50 \%$ de capacidade de retenção de luz.

O delineamento experimental foi em esquema fatorial de $2 \times 5$, ou seja, plântulas com zero e com um cotilédone, interagindo com cinco épocas de extrações: zero dia após a germinação (DAG), um DAG, dois DAG, quatro DAG e seis DAG com cinco repetições compostas por três sementes cada, totalizando 50 parcelas. Todas as parcelas foram dispostas de maneira casualizadas entre si.

As três sementes viáveis de feijão cultivar pérola foram semeadas em vasos plásticos com capacidade de $0,5 \mathrm{~L}$, contendo solo peneirado classificado como Argissolo Vermelho-Amarelo (Embrapa, 2013), com as seguintes características químicas: $\mathrm{pH} \mathrm{CaCl}_{2} 4,5$; $\mathrm{MO} \mathrm{g} \mathrm{dm}^{-3} 4,5$; $\mathrm{P}$ $\mathrm{mg} \mathrm{dm}^{-3}$ (resina) 6,0; $\mathrm{K} \mathrm{mmol} \mathrm{dm}^{-3}$ (resina) 4,6; Ca mmol $\mathrm{dm}^{-3}$ (resina) 10; $\mathrm{Mg} \mathrm{mmol}{ }_{\mathrm{c}} \mathrm{dm}^{-3}$ (resina) 4,0; $\mathrm{S}_{\left(\mathrm{SO}_{4}^{-2}\right)}$

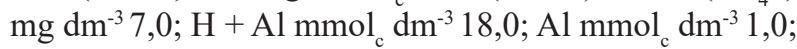
Soma de bases mmol $_{c} \mathrm{dm}^{-3} 15,6$; CTC mmol ${ }_{c}^{c} \mathrm{dm}^{-3} 36.6$; Saturação por bases (V\%) 50.8 e Saturação Al (m\%) 6,0 e adubado segundo Raij et al. (1997).

Foram montadas 75 parcelas a fim de garantir uma uniformidade nas plântulas, sendo selecionadas as 50 parcelas que apresentavam maior homogeneidade entre si. Foi desprezada uma plântula de cada parcela, deixando apenas as duas mais vigorosas em cada parcela.

Após a escolha das 50 parcelas, foi iniciado o experimento com os respectivos tratamentos. Durante o período experimental, todas as parcelas foram irrigadas até atingirem a capacidade de campo do solo, segundo metodologia descrita por Souza et al. (2000), e passaram por todos os tratamentos fitossanitários necessários.

Após 15 dias da instalação do experimento, foram avaliados os seguintes parâmetros: comprimento médio da raiz (CMR), comprimento médio da parte aérea (CMPA), diâmetro médio do caule (DMC), área foliar (AF), massa seca total da parte aérea (MSTPA) e massa seca total da raiz (MSTR). Para a determinação da MSTPA e da MSTR, todo material coletado passou por processo de secagem em estufa com circulação de ar forçada, com temperatura constante de $65^{\circ} \mathrm{C}$. Após 72 horas, esse material foi pesado em balança de precisão.

Também foram avaliados os parâmetros morfoanatômicos foliares, onde foi retirado um fragmento da região mediana do limbo foliar das folhas totalmente expandidas das plântulas germinadas. Cada fragmento com aproximadamente dois $\mathrm{cm}$ de comprimento foi fixado em F.A.A. 70 (formaldeído 37\%, ácido acético e etanol 70\% na proporção de 1,0: 1,0: 18,0 - V/V) por 24 horas. Após a fixação, foram lavados e armazenados em álcool 70\% até a data das análises. Os fragmentos foliares sofreram procedimentos de desidratação, diafanização, inclusão e emblocagem segundo Kraus \& Arduim (1997).

Com auxílio de um micrótomo de mesa, foram realizadas secções transversais de oito $\mu \mathrm{m}$ em cada fragmento foliar emblocado, contendo a nervura central. Para cada material emblocado foi realizada a montagem de uma lâmina histológica. Para essa montagem foi escolhida a primeira secção transversal que apresentou o material mais preservado, sem danos ou injúrias provocadas pelo corte nos tecidos vegetais. As secções escolhidas foram fixadas tendo como adesivo a albumina. As secções foram coradas com safranina a $1 \%$ e montadas em lâmina e lamínula com adesivo Entellan ${ }^{\circledR}$.

As medições dos parâmetros foliares foram realizadas na nervura central da folha. As lâminas foram observadas em microscópio óptico da marca Olympus ${ }^{\circledR}$ modelo BX43, contendo uma câmera acoplada para realização das fotografias dos cortes. As fotos foram utilizadas para as medições dos parâmetros anatômicos pelo programa de análise de imagem cellSens Standard ${ }^{\circledR}$, calibrado com régua microscópica nos mesmos aumentos das fotografias, segundo metodologia descrita por Pereira et al. (2008). Foram mensurados, segundo Carlquist (1975), os parâmetros foliares: diâmetro de floema (DF), diâmetro de xilema (DX), espessura da epiderme abaxial (EEAB) e espessura da epiderme adaxial (EEAD). As medições dos parâmetros foliares foram realizadas na nervura central da folha, sendo cada repetição representada pela média de 10 medições da mesma lâmina.

Os dados foram submetidos à análise de variância pelo teste $\mathrm{F}(\mathrm{p}<0,05)$, constatado significâncias, foram realizadas regressões polinomiais, considerando os fatores cotilédones e épocas de extrações como quantitativo, e a escolha do modelo para cada variável foi baseado na significância dos parâmetros e nos valores do $\mathrm{R}^{2}$, segundo Banzatto \& Kronka (2006).

\section{RESULTADOS E DISCUSSÃO}

Na figura 1 estão apresentadas as análises de regressões dos parâmetros comprimento médio de raiz, comprimento médio da parte aérea, diâmetro médio de caule e área foliar.

Observa-se na figura $1 \mathrm{~A}$ que o CMR aumentou linearmente em função da remoção dos cotilédones nas épocas de extrações para ambos os tratamentos. Da mesma 
maneira ocorreu nas figuras $\mathrm{B}$ e $\mathrm{D}$, porém, para esses parâmetros, o fator zero cotilédone foi negativamente mais severo para o feijoeiro. Em vista disso, observa-se que à medida que se antecipou os dias de extrações dos cotilédones, ficou evidenciada a necessidade da plântula em ter os mesmos presentes em seus primeiros dias após a germinação.

A remoção dos cotilédones pode ter originado uma carência de açúcar, pois, segundo Salles \& Buckeridge (2012) há uma regulação temporal entre a liberação dos açúcares via cotilédones e pela fotossíntese, dessa forma, a plântula inicia a fotossíntese ainda sob a degradação das reservas dos cotilédones, ou seja, haverá um período em que a plântula logrará de duas fontes de açúcares, cuja alternância pode se fazer necessária para suprir a sua demanda.

Dessa maneira, a raiz e a parte aérea juntamente com as folhas, que estavam com os seus tecidos em pleno crescimento, podem ter sido prejudicadas pela carência de energia e carbono, em virtude da ausência parcial ou total das reservas presentes nos cotilédones. Outro ponto a ser abordado, pode ser uma eventual escassez de compostos nitrogenados na plântula originados pela extração dos cotilédones, o que corroboram com Camargos et al. (2013)
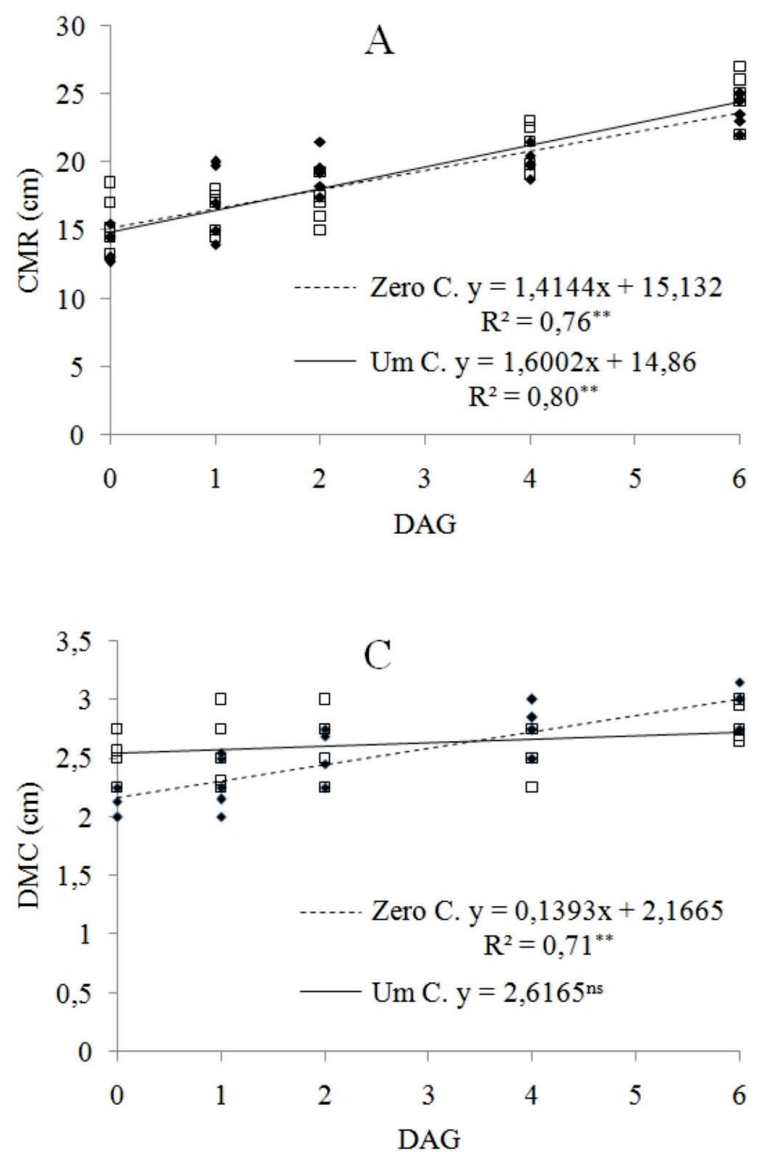

que, trabalhando com alocação de compostos nitrogenados de reserva durante a germinação de sementes de Canavalia brasiliensis Mart. ex Benth., constataram que aos dois dias após a germinação, o nitrato estava estritamente presente nos cotilédones, e posteriormente, despontou nos outros órgãos da plântula, indicando que o nitrato foi utilizado nos primeiros dias após a germinação para a síntese de compostos nitrogenados imprescindíveis para a constituição intracelular. Diante do exposto, é possível inferir que a remoção dos cotilédones prejudica o abastecimento de nutrientes, comprometendo o processo de síntese de novos compostos necessários para o desenvolvimento inicial da plântula.

Na figura $1 \mathrm{C}$ o diâmetro médio do caule aumentou linearmente com os dias após a emergência somente para zero cotilédone, apresentando menor diâmetro a zero dia após a germinação. Já para um cotilédone não foi observado esse efeito, o que demonstra um suprimento adequado de nutrientes para a plântula mesmo com apenas um cotilédone. Resultados semelhantes foram observados por Bonfil (1998) que, trabalhando com os efeitos causados pelo tamanho das sementes e herbivoria nos cotilédones em plântulas de Quercus rugosa Née. e Quercus laurina Bonpl. (Fabaceae), constataram que a altura, o diâmetro de caule
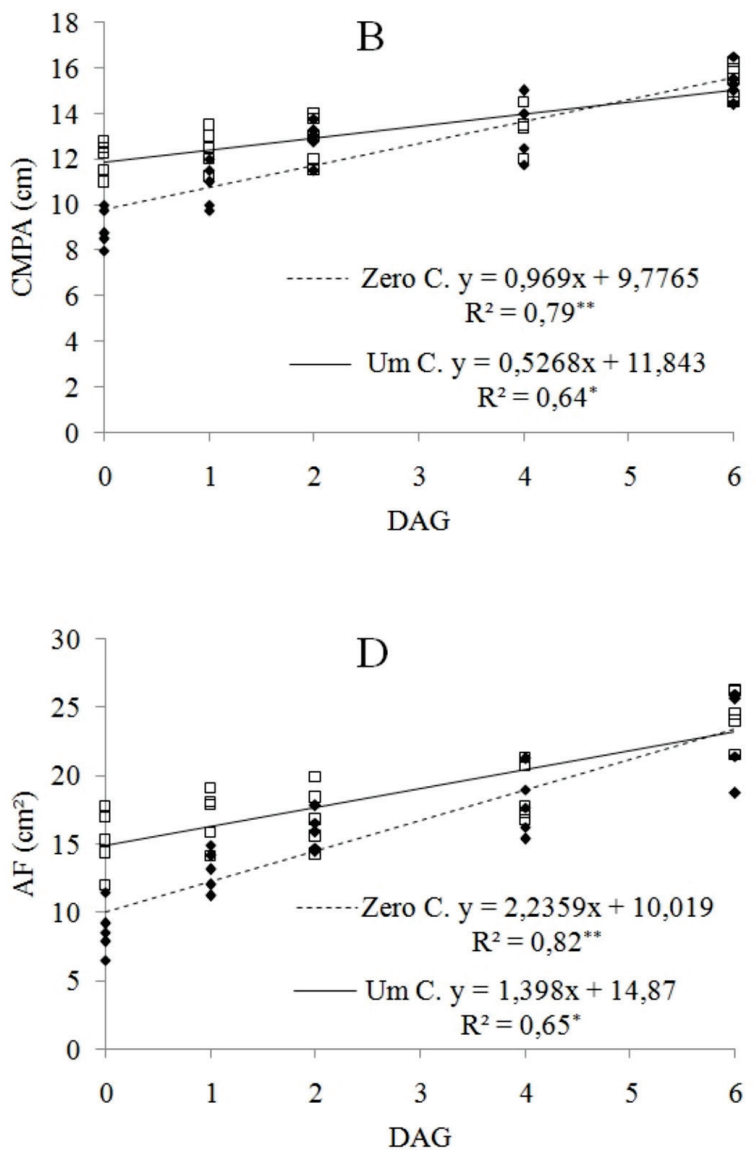

Figs. 1 A-D. Análise de regressão de plântulas de Phaseolus vulgaris L. A. Comprimento médio de raiz (CMR); B. Comprimento médio da parte aérea (CMPA); C. Diâmetro médio de caule (DMC); D. Área foliar (AF). C: cotilédone (** significativo a 1\% de probabilidade de erro, * significativo a $5 \%$ de probabilidade de erro e ${ }^{\text {ns }}$ não significativo). 

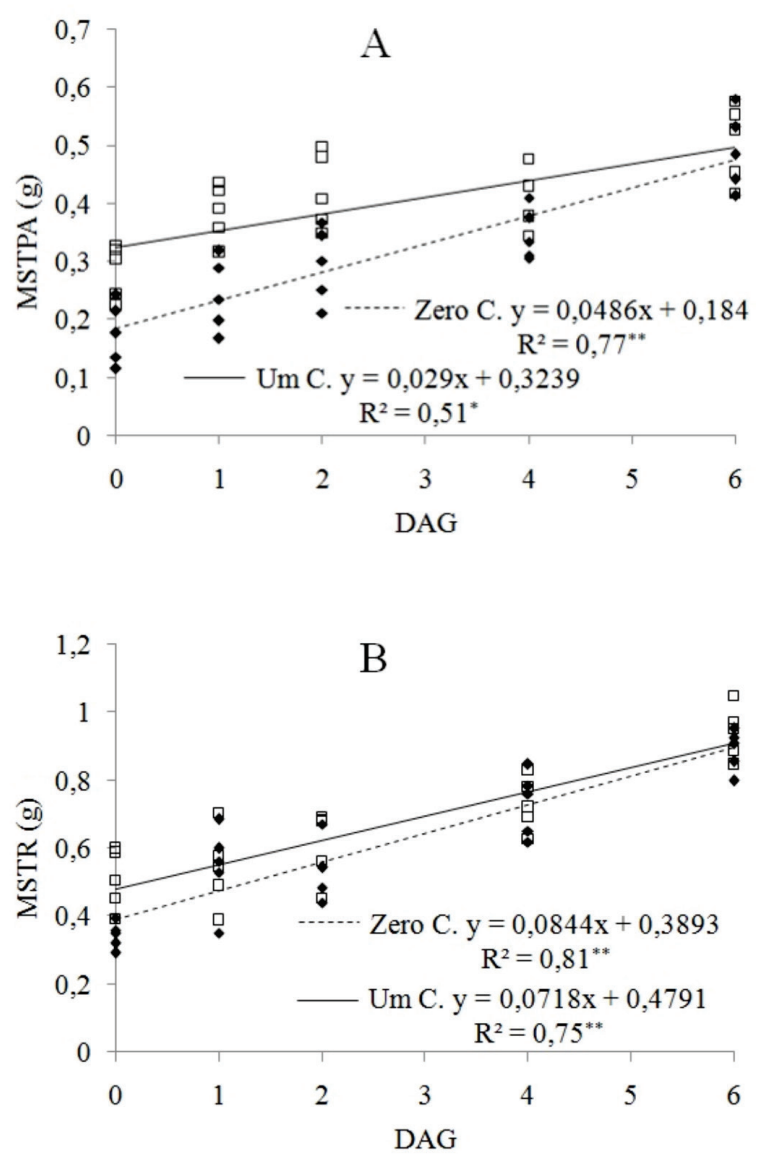

Figs. 2 A-B. Análise de regressão de plântulas de Phaseolus vulgaris L. A. Massa seca total da parte aérea (MSTPA); B. Massa seca total da raiz (MSTR). C: Cotilédone (** significativo a $1 \%$ de probabilidade de erro e * significativo a $5 \%$ de probabilidade de erro).

e a sobrevivência das plântulas foram bruscamente afetadas pela remoção dos seus cotilédones, cujo procedimento foi realizado um mês após a germinação.

De acordo com Sakpere et al. (2015) a remoção de cotilédones na abóbora plissado (Telfairia occidentalis Hook. F.) provocou reduções significativas no crescimento das plântulas e na sua biomassa em todas as fases de remoção. Já Yi et al. (2015), trabalhando com remoção de cotilédones de sementes maduras de Quercus mongolica Fisch. ex Turcz., observaram que a taxa de germinação não foi afetada com $65 \%$ dos cotilédones removidos, porém, quando essa remoção foi de $70 \%$ causou uma queda drástica na taxa de sobrevivência.

Na figura 2 estão apresentadas as análises de regressões dos parâmetros massa seca total da parte aérea e massa seca total da raiz.

Nas figuras 2A-B foi verificado que os parâmetros aumentaram linearmente em função da remoção dos cotilédones nas épocas de extrações para ambos os tratamentos, sendo mais severo com o fator zero cotilédone. A perda de ambos os cotilédones foi mais prejudicial para o volume de massa da plântula. De acordo com Fukumoto \& Kajimura (2000), trabalhando com efeitos da predação de insetos, a sobrevivência de hipocótilos e radículas de Quercus variabilis
Blume é afetada pela perda dos seus cotilédones, o que também pode explicar os efeitos negativos encontrados para os parâmetros MSTPA e MSTR neste trabalho, principalmente na primeira fase de remoção em ambos os tratamentos. Resultados semelhantes foram encontrados por Hayashi et al. (2012), estudando a influência da remoção dos cotilédones no desenvolvimento inicial de plântulas das espécies Canavalia ensiformis (L.) DC. e Phaseolus vulgaris, onde verificaram que as plântulas de ambas espécies que permaneceram por menor período com os cotilédones apresentaram valores inferiores para massa seca em relação as que ficaram por mais tempo com os cotilédones.

Na figura 3 estão apresentadas as análises de regressões dos parâmetros diâmetro de floema, diâmetro de xilema, espessura da epiderme abaxial e espessura da epiderme adaxial.

Nas figuras 3A-D foi observado que os parâmetros aumentaram linearmente em função da remoção dos cotilédones no decorrer das épocas de extrações, sendo mais severo o fator com zero cotilédone, ou seja, os efeitos provocados pela remoção dos cotilédones nos parâmetros DF, DX, EEAB e EEAD resultaram em um espaçamento celular cada vez menor à medida que se antecipou os dias de extrações dos cotilédones. 

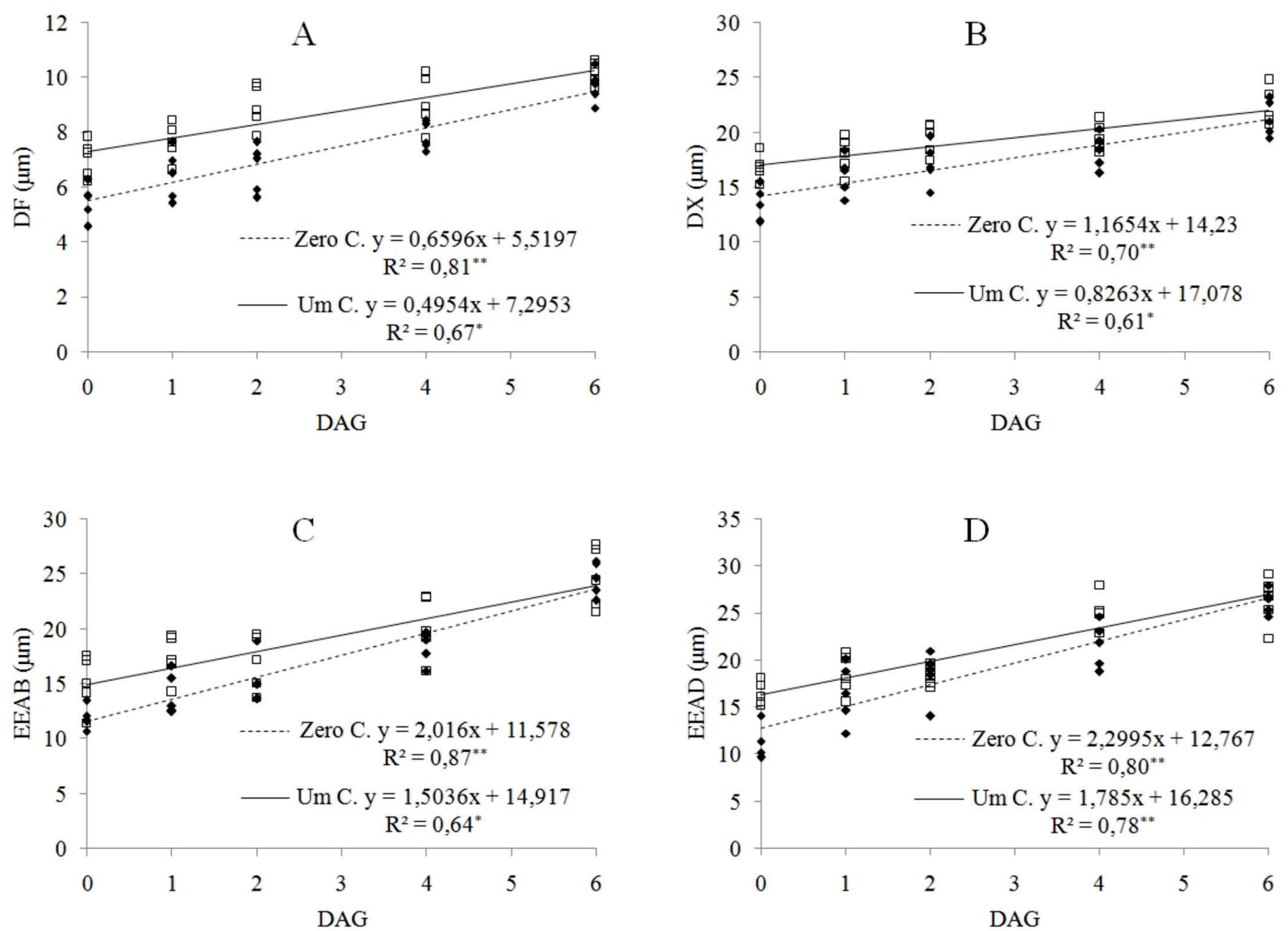

Figs. 3 A-D. Análise de regressão de plântulas de Phaseolus vulgaris L. A. Diâmetro do floema (DF); B. Diâmetro do xilema (DX); C. Espessura da epiderme abaxial (EEAB); D. Espessura da epiderme adaxial (EEAD). C: cotilédone (** significativo a 1\% de probabilidade de erro e * significativo a $5 \%$ de probabilidade de erro).

Dessa maneira, infere-se que os nutrientes fornecidos pelos cotilédones na fase inicial de seu desenvolvimento são imprescindíveis na constituição de eficientes órgãos sem provocar danos aos seus tecidos. O menor desenvolvimento dos tecidos responsáveis pelo transporte de seivas leva a ineficiência da distribuição dos nutrientes no organismo vegetal, o que pode desencadear um menor crescimento do feijoeiro, conforme apresentado nas figuras $1 \mathrm{~A}-\mathrm{B}$ e $\mathrm{D}$ e também nas figuras 4A-J, que evidenciam o efeito danoso em geral causado pela remoção dos cotilédones nas diferentes épocas de remoção.

$\mathrm{Na}$ figura 5 estão elucidados os danos provocados nos tecidos, onde o efeito do número de cotilédones é enfatizado quando comparadas as figuras 5A-F. Quanto à época de remoção, esse efeito é observado entre as figuras $5 \mathrm{~A}-\mathrm{E}$ e entre as figuras $5 \mathrm{~F}-\mathrm{J}$. As plântulas que dispõem de epidermes mais espessas estão menos sujeitas a danos mecânicos e a herbivoria causada por larvas de insetos, devido proporcionar uma barreira física às folhas, assim aumentam as suas chances de sobrevivência, principalmente na fase inicial de seu desenvolvimento (Viana et al. 2015).
Em função disso, o entendimento das modificações macro e micromorfológicas dos órgãos e tecidos dos vegetais, assim como os efeitos provocados pelas mesmas, devem ser cada vez mais estudados, a fim de melhorar o entendimento e direcionamento das pesquisas pertinentes ao tema (Lisboa et al. 2013). A sintomatologia é muito utilizada para avaliação dos danos causados por fatores bióticos ou abióticos. Neste caso, aspectos estruturais auxiliam na compreensão dos mecanismos que provocam as injúrias nas plantas (Moreira \& Isaias 2008).

Mediante os resultados obtidos neste trabalho, concluise que a remoção dos cotilédones no desenvolvimento inicial do feijoeiro influência os seguintes parâmetros: comprimento médio de raiz e parte aérea; área foliar; massa seca total da parte aérea e raiz; diâmetro do floema e xilema; espessura da epiderme abaxial e adaxial. $\mathrm{O}$ diâmetro médio do caule não é influenciado com a remoção de um cotilédone. Dessa forma, a herbivoria nos cotilédones do feijoeiro, principalmente nos primeiros dias de extração, dificulta o desenvolvimento inicial do feijoeiro, assim como o torna mais suscetível ao meio. 

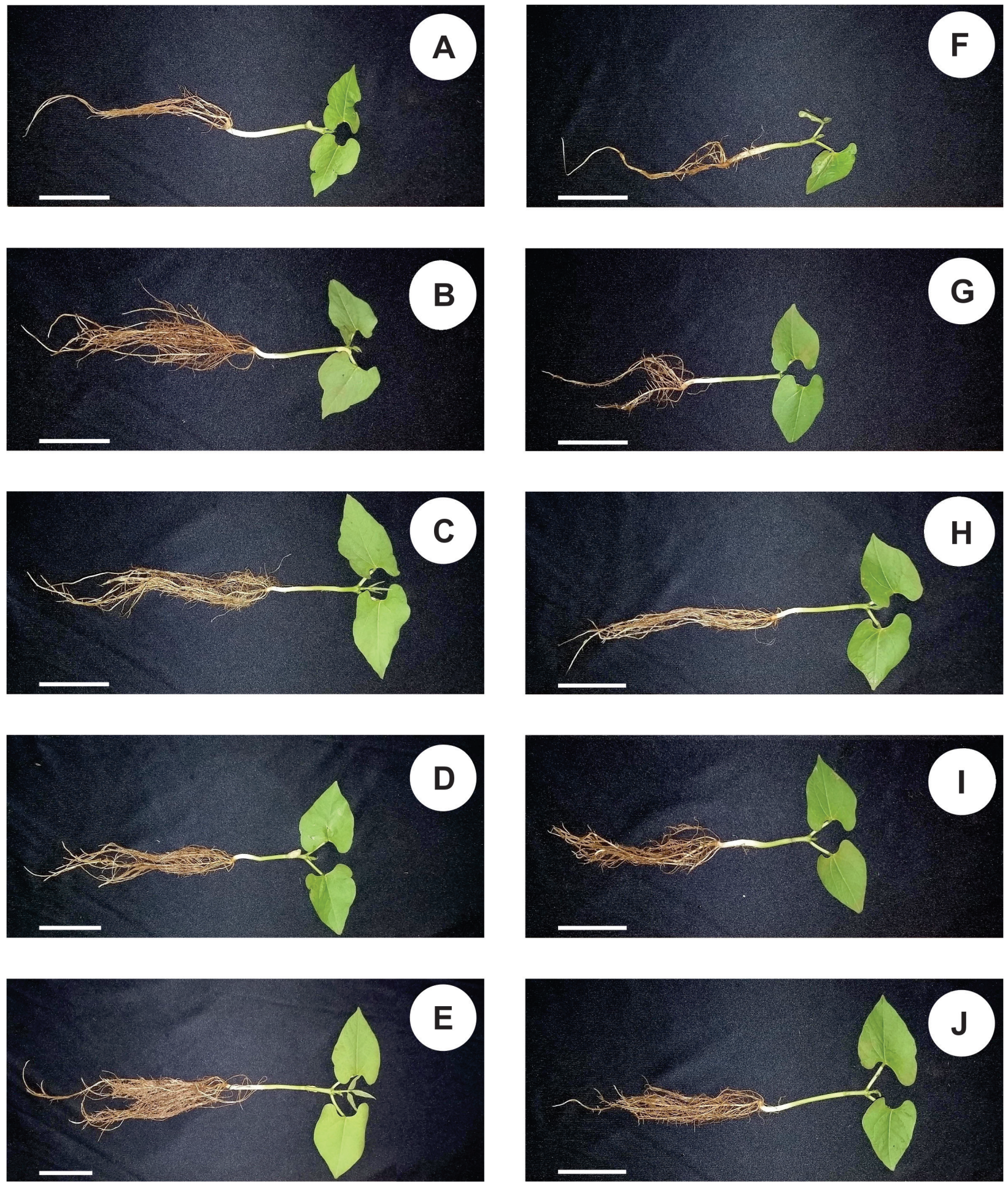

Figs. 4 A-J. Plântulas de Phaseolus vulgaris L. aos 15 DAG. A. Um cotilédone a zero DAG; F. Zero cotilédone a zero DAG; B. Um cotilédone a um DAG; G. Zero cotilédone a um DAG; C. Um cotilédone a dois DAG; H. Zero cotilédone a dois DAG; D. Um contilédone a quatro DAG; I. Zero cotilédone a quatro DAG; E. Um cotilédone a seis DAG; J. Zero cotilédone a seis DAG. Barras $=5 \mathrm{~cm}$ 

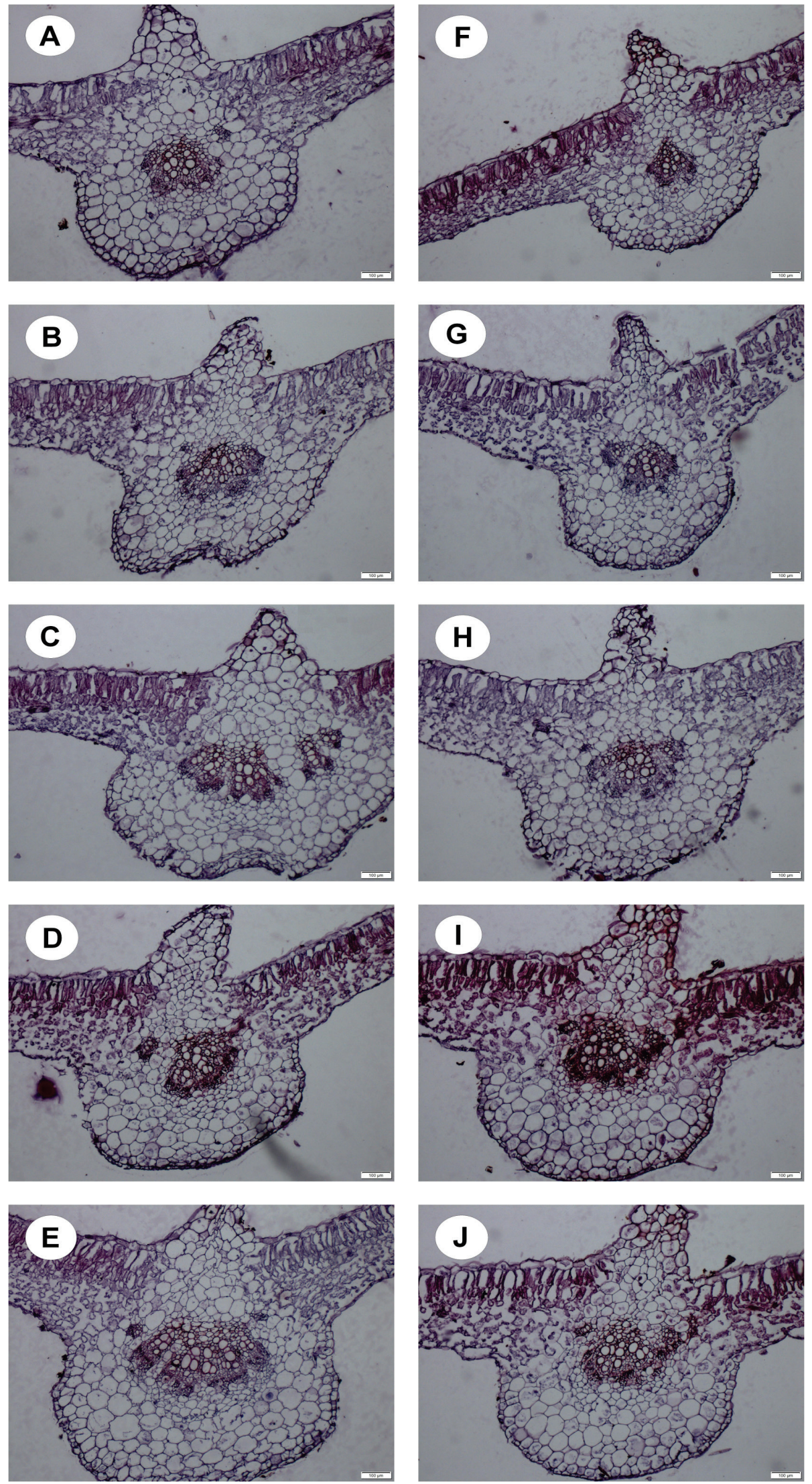

Figs. 5 A-J. Cortes transvesais de folha de Phaseolus vulgaris L. aos 15 DAG. A. Um cotilédone a zero DAG; F. Zero cotilédone a zero DAG; B. Um cotilédone a um DAG; G. Zero cotilédone a um DAG; $\mathbf{C}$. Um cotilédone a dois DAG; H. Zero cotilédone a dois DAG; D. Um contilédone a quatro DAG; I. Zero cotilédone a quatro DAG; E. Um cotilédone a seis DAG; J. Zero cotilédone a seis DAG. Barras $=100 \mu \mathrm{m}$ 


\section{REFERÊNCIAS}

Alwathnani, H.A., Perveen, K., Tahmaz, R. \& Aalhaqbani, S. 2012. Evaluation of biological control potential of locally isolated antagonist fungi against Fusarium oxysporum under in vitro and pot conditions. African Journal of Microbiology Research 6(2):312-319.

Banzatto, D.A. \& Kronka, S.N. 2006. Experimentação agrícola. Fundação de Apoio a Pesquisa, Ensino e Extensão, Jaboticabal. 237 p.

Barbosa, F.R. \& Gonzaga, A.C.O. 2012. Informações técnicas para o cultivo do feijoeiro - comum na Região Central-Brasileira: 2012-2014. Santo Antônio de Goiás, Embrapa Arroz e Feijão, Santo Antônio de Goiás. Documentos 272, 247p.

Bonfil, C. 1998. The effects of seed size, cotyledon reserves, and herbivory on seedling survival and growth in Quercus rugosa and $Q$. laurina (Fagaceae). American Journal of Botany 85:79-87.

Camargos, L.S., Soares, C.R.S., Justino, G.C. \& Aguiar, L.F. 2013. Alocação de compostos nitrogenados de reserva durante a germinação de sementes de Canavalia brasiliensis. Biotemas 26(4):1-10.

Carlquist, S. 1975. Ecological strategies of xylem evolution. University of California Press, Berkeley. 245p.

Empresa Brasileira de Pesquisa Agropecuária - Embrapa. 2013. Sistema brasileiro de classificação de solos. Embrapa Solos, Brasília. 353p.

Fukumoto, H. \& Kajimura. 2000. H. Effects of insect predation on hypocotyls survival and germination success of mature Quercus variabilis acorns. Journal of forest research 5:31-34.

Hayashi, A.M., Malaguetta, H. \& Agostini, K. 2012. Influência da remoção dos cotilédones no desenvolvimento inicial de plântulas de Canavalia ensiformis e Phaseolus vulgaris (Leguminosae, Papilionoidae). Bioikos 26(2):63-70.

Iortsuun, D.N., Chia, A.M. \& Adeola, A.F. 2008. The effect of seed mass and cotyledon removal on the germination and growth of fluted pumpkin (Telfaria occidentalis Hook.F.). Science World Journal 3(1):25-31.

Kraus, J.E. \& Arduin, M. 1997. Manual básico de métodos em morfologia vegetal. Editora Universidade Rural, São Paulo. 198 p.
Lisboa, L.A.M., Ramos, S.B., Viana, R.S., Heinrichs, R., Segati, D.F. \& Figueiredo, P.A.M. 2013. Modificações morfoanatômicas foliares da cana-de-açúcar em função de estratégias de aplicação de herbicidas. Sociedade dos Técnicos Açúcareiros e Alcooleiros do Brasil 31(3):3336.

Moreira, A.S.F.P. \& Isaias, R.M.S. 2008. Comparative anatomy of the absorption roots of terrestrial and epiphytic orchids. Brazilian archives of biology and technology 51(1):83-93.

Pereira, F.J., Castro, E.M., Souza, T.C. \& Magalhães, P.C. 2008. Evolução da anatomia radicular do milho 'Saracura' em ciclos de seleção sucessivos. Pesquisa Agropecuária Brasileira 43(12):1649-1656.

Raij B. van, Cantarella H., Quaggio, J.A. \& Furlani, A.M.C. 1997. Recomendações de adubação e calagem para o Estado de São Paulo. Boletim Técnico 100. Fundação Instituto Agronômico, de Campinas, Campinas. 286p.

Sakpere, A.M.A., Ajayi, S.A. \& Adelusi, A. 2015. Cotyledon persistence and seedling growth in fluted Pumpkin (Telfairia occidentalis Hook. F.). International Journal of Biological And Chemical Sciences 9(2):593-602.

Salles, I.S. \& Buckeridge, M.S. 2012. Coordenação temporal da degradação das reservas dos cotilédones de jatobá (Himenaea courbaril L.). Revista da Biologia 9(3):50-52.

Souza, C.C., Oliveira, F.A., Silva, I.F. \& Amorim neto, M.S. 2000. Avaliação de métodos de determinação de água disponível e manejo da irrigação em terra roxa sob cultivo de algodoeiro herbáceo. Revista Brasileira de Engenharia Agrícola e Ambiental 4(3):338-342.

Viana, R.S.; Figueiredo, P.A.M.; Lisboa, L.A.M. \& Pascoaloto, I.M. 2015. Características morfoanatômicas de folhas de cana-de-açúcar sob efeito residual de maturadores. Revista Brasileira de Herbicidas 14(4):306-314.

Yi, X., Wang, Z., Liu, C., Liu, G. \& Zhang, M. 2015. Acorn cotyledons are larger than their seedlings' need: evidence from artificial cutting experiments. Scientific reports 5:8112. 